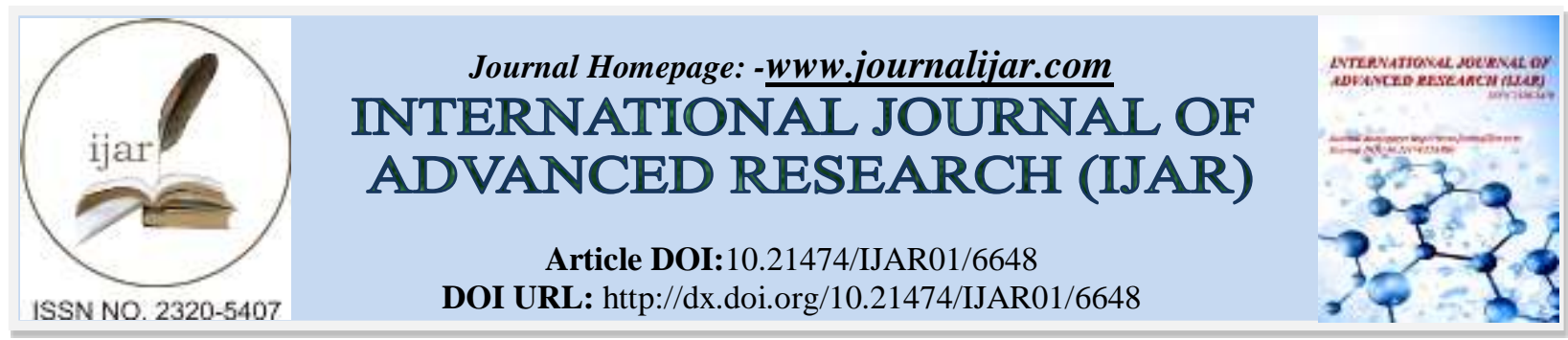

RESEARCH ARTICLE

\title{
PROFESSIONAL STRESS AS A DETERMINING FACTOR FOR THE QUALITY OF NURSING CARE IN NEUROLOGICAL HOSPITAL CARE IN BULGARIA.
}

Lidia Mladenova Georgieva ${ }^{1}$, Velichka Tsvetanova Atanasova ${ }^{2}$ and Boryana Borisova ${ }^{3}$.

1. MD, MPhil, PhD, Faculty of Public Health, Medical University of Sofia, Bulgaria.

2. PhD student, Faculty of Public Health, Medical University of Sofia, Bulgaria.

3. PhD, Faculty of Public Health, Medical University of Sofia, Bulgaria.

\section{Manuscript Info}

Manuscript History

Received: 02 January 2018

Final Accepted: 04 February 2018

Published: March 2018

Keywords:-

Professional Stress, Nurses, Quality, Health Care.

\section{Abstract}

Summary: The professional stress of the nurses is one of the main criteria in determining the quality of nursing care in neurological hospital care.

Aim: The purpose of this study is to investigate the professional stress of nurses in neurological clinics and wards in Bulgaria.

Methodology: The survey was conducted through a direct anonymous questionnaire during the period June 2016 - February 2017. The respondents are 100 nurses (out of 136) working in the neurological wards of nine hospitals in Bulgaria, selected on a lottery basis.

Results: The results show staff shortages reported in 53, 8\%, psychoemotional exhaustion among nurses in $64 \%$ and stress at work in (64, $1 \%)$. More than one-third of respondents are reporting for a lacking willingness to work. Occupational exhaustion is presented as psychoemotional exhaustion, accompanied by low professional motivation and dissatisfaction.

Conclusions: The specific nature of the professional activity of the nurses in neurological hospital care provokes the development of the syndrome of professional exhaustion, which requires timely prevention. This help must be comprehensive, psychological and organizational.

Copy Right, IJAR, 2018,. All rights reserved.

\section{Introduction:-}

The occupational stress worldwide is a leading paradigm of psychological and psychiatric societies and is relevant and important for improving quality and efficiency of work and nursing care in neurological hospitals. [4][Borisov, V.]

Occupational safety and health are defined as occupational stresses, "Emotional, cognitive, behavioral, and psychological responses to negative aspects that arise from inconsistencies between work requirements and the ability and needs of the worker. These negative reactions can become a lasting conditions characterized by suffering, apathy, indifference, and often with a sense of impasse. "[6,10,12][Savova, S. et all.]

In 1974, Herbert Freydenberger, an American psychiatrist and psychologist, formulates the term "burnout" as a characteristic of a psychological state in healthy people who work in an emotionally tense work environment. He 
defines the concept of Professional Burning as "Exhaustion of energy in professionals in health and social assistance when they feel overwhelmed by the problems of the people they work with." $[14,15,16]$ [. Maddi, S.R. et all.]

"Bornout syndrome" does not exist as a diagnosis but is mentioned in the annex to the Xth revision of the International Conference on Diseases Code Z73.0 as a factor affecting health status. The pathology of occupational stress is summarized in the term "Bornout" and is associated with more significant occupational problems. [6,8,9] [Savova, S. et all.]

Stress-inducing factors or so-called stressors, in occupational stress, according to Sellier, are the result of the exogenous and endogenous environment.

As factors of occupational stress can be determined:

1. Internal emotional factors;

2. The human factor (nurses);

3. The working environment (clinic / department of nervous diseases).

4. Occupational stress as stressors can also manifest:

5. The technical working environment;

6. The social environment;

7. Professional appearance $[1,2,10,15]$ [Balkanska, P. et all.].

When a nurse has a feeling of control over the situation, stress can be motivating, whereas in the opposite scenario, when the nurse feels that she loses control, position or is considered insignificant, it significantly worsens the quality of nursing care. Stress is not only threatening, but very quickly unlocks its grades and the nurse develops a Burnoutout syndrome [7,11] [Nisheva, V.et all.].

Active occupational stress is mentioned when in a given medical establishment, in the case of neurological clinics / departments, there are developed high turnover levels of trained and executed personnel, ie. nurses who are dissatisfied with their work despite the high level of professional qualifications and continuing education [5,7] [Georgieva, El.et all.].

The topic of occupational stress as a determining factor for the quality of nursing care is imperative for a reform of the existing practice in the direction of increasing its efficiency and cost-effectiveness. The lack of a normative basis and a comprehensive study of the professional stress of nurses in neurological hospital care and the significance of the problem at present, are grounds for conducting this study.

Aim:-

To investigate the professional stress of nurses in neurological clinics / wards in Bulgaria. On the base of this to develop recommendations that provide better quality nursing care.

\section{Methodology:-}

This article presents an analysis of a sociological survey conducted by a direct anonymous questionnaire, between June 2016 and February 2017.

Twelve neurological clinics / wards were selected from all existing in Bulgaria on a lottery principal. The questionnaires were sent to all of them. We received back filled in questionnaires from 9. Four of them were University Multiprofile Hospitals for Active Treatment (UMHAT) and five Municipal Multiprofile Hospitals for Active treatment (MMHAT): UMHAT "G. Stranski" - Pleven, University of Medicine and Pharmacy "St. George" Plovdiv, UMHAT - Rousse, UMHAT - Bourgas, Trakia Hospital - Stara Zagora, MOBAL "S. Cherkezov "- V. Tarnovo," St. Ivan Rilski "- Dupnitsa, University Hospital" St. Petka "- Vidin," Sveta Anna "Hospital - Varna.

The respondents were 100 neurological nurses out of 136 to whom a questionnaire were geivn.

This article presents the results of a part of the stress-related questionnaire containing 90 questions exploring quality of neurology nurse care. The questionnaire consists of the following sections:

1. General information on respondents.

2. Quality of Nursing Care (including stress). 
3. Work (including stress) and training of the nurses surveyed.

The survey data was entered and processed with the Statistical Package for Social Sciences (SPSS for Windows, Version 13.0). Descriptive statistical methods, methods for hypothesis testing, Mann-Whitney test were for comparison of independent groups (UMHAT and MMHAT) were used.

\section{Results:-}

The majority of the respondents were women - 95.8\%, which is representative for the real gender distribution of the nurses in Bulgaria. In terms of age, the largest proportion of respondents are were in the age group 55-65 years $(28.1 \%)$, which is representative for the process of aging among nurses. Nearly $40 \%$ of respondents have bachelor degree and 13.8 are masters. Over $80 \%$ of respondents had a total length of service over 10 years. More than 10 years of experience in the neurological ward had $53.7 \%$ of the respondents, and only $2.1 \%$ were nurses with work experience of up to one year in a neurological ward, which shows the relatively low interest and motivation of the nurses to work in the neurological clinics in Bulgaria.

More than one third of the surveyed nurses (38\%) reported that they are unwilling to go to work in the morning, but $61.8 \%$ have a willingness to work each morning or several times a week. The data reflect the willingness to work and accordingly, the motivation and positive attitude of the nurses towards their professional activity.

Nearly $64 \%$ of staff at the University Hospitals reported to feel exhausted every day or several times per week at the end of the working day. The Municipality hospitals respondents had a feeling of exhaustion at the end of the working day in about $19 \%$ every day or several times a week.

The interviewed nurses from the University Hospital have the feeling of stress every day or weekly in about $36 \%$. Respondents working at the Municipality Hospitals feel stressed at work each day and several times a week in $18 \%$.

Table 1:- How often the number of neurological nurses is adequate to the number of patients they care for, according to the nurse's opinion

\begin{tabular}{|l|c|c|c|}
\hline Answer & n & \% & Grouped \% \\
\hline Rarely & 6 & 6,4 & 46,2 \\
\hline Sometimes & 37 & 39,8 & \multirow{2}{*}{53,8} \\
\hline Very often & 26 & 28,0 & \\
\hline Always & 24 & 25,8 & 100,0 \\
\hline Totally replied & 93 & 100,0 & \\
\hline
\end{tabular}

The opinion of more than half of the respondents $(53.8 \%)$ was that there is a shortage of staff always or very often in the neurological wards. This is a serious organizational problem, which is an obstacle for ensuring high quality nursing care and the need to solve it is beyond dispute. [Tab. 1]

Table 2:- Distribution of respondents according to the feeling of end-of-work exhaustion at the UMHAT and MMHAT

\begin{tabular}{|c|c|c|c|c|}
\hline I feel exhausted at the end of the working day & UMHAT & MMHAT & Total & p \\
\hline Never & $1(1,8)$ & $3(7,9)$ & $4(4,3)$ & \multirow{7}{*}{$\frac{\mathbf{p}}{0,002}$} \\
\hline Several times a year or less & $4(7,3)$ & $7(18,4)$ & $11(11,8)$ & \\
\hline Once a month or less & $3(5,5)$ & $3(7,9)$ & $6(6,5)$ & \\
\hline Several times a month & $6(10,9)$ & $9(23,7)$ & $15(16,1)$ & \\
\hline Once a week & $6(10,9)$ & $9(23,7)$ & $15(16,1)$ & \\
\hline Several times a week & $12(21,8)$ & $5(13,2)$ & $17(18,3)$ & \\
\hline Every day & $23(41,8)$ & $2(5,3)$ & $25(26,9)$ & \\
\hline
\end{tabular}

The data from the comparative analysis of the responses of the nurses working in the neurological clinics in the UMHAT and MMHAT showed a significant difference. Nearly $64 \%$ of neurology nurse staff working in the UMHAT and only about $19 \%$ of those working in MMHAT reported that they feel exhausted every day and several times a week at the end of the working day. Existence of psycho-emotional exhaustion was found to a greater extent among the responding nurses working in the UMHAT [Tables 2]. 


\section{Discussions:-}

The results found in the reported study were indicative for the higher workload of nurses in the neurological clinics / wards of the University Hospitals in Bulgaria, because of the decreased number of human resources (neurological nurses).This state of nursing can be described as close to the so called Burnout syndrome (syndrome of professional exhaustion), which is a negative fact and factor for the quality of nursing care.

Similar results have been found in studies conducted by I. Georgieva et. all. on professional exhaustion of nurses working at the clinic of child and genetic diseases at a University hospital in Plovdiv" . The data reported for psycho-emotional exhaustion of $48 \%$ of the 46 nurses surveyed, with $70 \%$ claiming they are burdened with many responsibilities and feel tired at the end of the working day, and 20\% report that they always get tired of work . [10] [Georgieva, I. et all].

Similar results were found in the study by M. Todorova and V. Mikhailova on professional satisfaction and psychoemotional burnout in health care professionals, in which 96 healthcare professionals were interviewed (the largest share $68.43 \%$ were nurses). More than half of the professionals surveyed reported that very often in the morning they do not wake up with wishes for work, and at the end of the day they feel used. According to the authors professional stress has a negative impact on psychophysiological state of health professionals and manifests as persistent fatigue, irritability forgetfulness when communicating. [9] [Todorova, M. et all.]

\section{Conclusions and recommendations:-}

The main reasons for the professional burnout of neurological nurses seems to be the daily professional stress, the lack of recognition and low professional satisfaction, the lack of autonomous functions, and very importantly, the insufficient human resources and the increased volume of work especially in the clinics of the University Hospitals. The specific nature of the professional activity of the nurses in neurological hospital care provokes the development of the syndrome of professional exhaustion, which requires timely prevention. This help must be comprehensive, psychological and organizational.

Improving working conditions, both in material and psychological terms is a leading point in the prevention of occupational stress.

\section{Recommendations:-}

1. Improvement of the working conditions - psychological and organizational;

2. Selection of qualified nurses adequate to the number of patients hospitalized in the neurological ward, especially in the neurology clinics surveyed in the UMHAT;

3. It is necessary for nurses to participate in organized lectures, seminars and discussions as well as practical exercises, in order to acquire knowledge and psychological skills to prevent occupational stress;

4. In this respect, there is a clear need for new thorough studies and analyzes of the psycho-emotional problems of nursing staff in neurological hospitals. Only on the base of such analyzes, the conditions and organization of nursing work could be improved according to the specifics of work in neurological hospital care.

\section{Literature:-}

1. Balkanska, P., Nonverbal Behavior - an Essential Element in the Psychological Training of Health Specialists, TEMPTO, Sofia, 2011, 80-86

2. Balkanska, P., J. Hristov, M. Alexandrova, Teamwork and Team Interaction, In: Medical Pedagogy, EKSPRES, Gabrovo, 2010

3. Georgieva, El., S. Savova, Em. Georgieva, Prevention of Occupational Stress and Techniques for Coping With It, ING, Sofia, 2016, 80-86

4. Borisov, V., Quality of Health Care, C: Social Medicine, Textbook for Medical Colleges, Akar PRINT, S., 2004, 125-127.

5. Georgieva, El., S. Savova, Em. Georgieva, Psychosocial Approaches to Stress Management at the Healthcare Institution, ING, Sofia, 2015, 63-69

6. Savova, S., Prevention of Stress and Vocational Exhaustion, Simolini 94, 2012

7. Nisheva, V., K. Georgieva, E. Dimitrova, P. Hristova. Burnout Syndrome in Nursing, Sisterhood, 36, 2004, No 4, 3-9

8. Shipkovensky, N., Yatrogenia or relieving psychotherapy, East-West, Sofia, 2016, 56-63 
9. Todorova, M., V. Mihailova. Professional Satisfaction and Psycho-emotional Burning in Medical Professionals, Management and Education, Volume IV (3) 2008, 168-172

10. Georgieva, I., E. Karaslavova, D. Todorova. Professional exhaustion of nurses working at the Clinic of Child and Genetic Diseases at the University Hospital "St. George" - Plovdiv, Sister Work, 40, 2008, No 3, 3-7

11. Strategy for Development of Health Care in Bulgaria 2013-2020.

12. Cohen, S., Wills, T. A., Stress Social Support, and the Buffering Hypothesis, Psychological Bulletin, 98,2015

13. Felton, B., Rewenson, T., Hinrichsen, G., Stress and coping in the explanation of psychological adjustment among chronically ill adults. Social Science and Medicine, 2013

14. Maddi, S.R., Kobasa, S.C., The Hardy Executive: Health and Stress, Dow Jones-Irwin, Homewood, III 2014

15. Obasa, S.C., Puccetti, M.C., Personality and social resources in stress resistanse. Journal of Personality and Social Psychology, 2013

16. stresizdrave.mvt.bg

17. Todorova, M., V. Mihailova. Professional Satisfaction and Psycho-emotional Burning in Medical Professionals, Management. 